\title{
Effect of Environment on Microstructure Evolution and Friction of Au-Ni Multilayers
}

\author{
Ebru Cihan $^{1}$ (1) $\cdot$ Katherine Jungjohann ${ }^{2} \cdot$ Nicolas Argibay $^{3} \cdot$ Michael Chandross $^{3} \cdot$ Martin Dienwiebel $^{1,4}$ (1)
}

Received: 29 August 2019 / Accepted: 9 November 2019 / Published online: 29 January 2020

(c) This is a U.S. government work and not under copyright protection in the U.S.; foreign copyright protection may apply 2020

\begin{abstract}
We present results from a systematic investigation of environmental effects on the frictional behavior of Au-Ni multilayer films of varying interlayer spacing. The current results, sliding against ruby spheres in a dry $\mathrm{N}_{2}$ atmosphere, are compared to prior work on the tribological behavior of these materials under ultra-high vacuum (UHV) (Cihan et al. in Sci Rep 9:1-10, 2019). Under both conditions, there is a regime of high friction when the interlayer spacing is large and a regime of low friction when the spacing is small. The low friction regime is associated with a critical grain size below which grain boundary sliding is expected to be the dominant mechanism of deformation. A shear-induced alloy formation (60-65 at.\% Ni in $\mathrm{Au}$ ) and a concomitant low friction coefficient was observed with multilayer spacings of $20 \mathrm{~nm}$ and lower under UHV. A distinct microstructure was found in dry $\mathrm{N}_{2}$, and is attributed to different interfacial characteristics due to adsorbed species; rather than mixing between $\mathrm{Au}$ and Ni layers, only the uppermost Au layers were affected by shearing. These observations are coupled with the friction and wear behavior of multilayer samples sliding under different environments.
\end{abstract}

Keywords Multilayer $\cdot$ Au-Ni $\cdot$ Friction $\cdot$ Plasticity $\cdot$ Dislocation $\cdot$ Grain boundary $\cdot$ Nanocrystalline

\section{Introduction}

Martin Dienwiebel

martin.dienwiebel@kit.edu

Ebru Cihan

ebru.cihan@ap.physik.uni-giessen.de

Katherine Jungjohann

kljungj@sandia.gov

Nicolas Argibay

nargiba@sandia.gov

Michael Chandross

mechand@sandia.gov

1 Institute for Applied Materials-Computational Materials Science (IAM-CMS), Karlsruhe Institute of Technology (KIT), 76131 Karlsruhe, Germany

2 Center for Integrated Nanotechnologies (CINT), Sandia National Laboratories, Albuquerque, NM 87185, USA

3 Material, Physical, and Chemical Sciences Center, Sandia National Laboratories, Albuquerque, NM 87185, USA

4 Fraunhofer Institute for Mechanics of Materials (IWM), MicroTribology Center $\mu$ TC, 79108 Freiburg, Germany
The environmental conditions under which tribological materials operate in industrial applications are generally not the same as those used during the process design. For example, special sliding components operated under ultrahigh vacuum (UHV) conditions (i.e., in space technology or in lithography) must be designed to provide low friction under vacuum [1]. Moreover, fundamental friction studies and atomistic simulations are often performed in a vacuum environment in order to reduce the complexity of the observed phenomena and the computational effort, even though these are not the conditions under which the application may operate [2].

However, the environment can have a profound impact on the friction and wear of the contacting material surfaces, as adsorbed contaminants can cause changes at the asperity level and so-called third bodies [3] are generated with different chemical compositions and morphologies [4]. Therefore, it is important to understand the environmental effects on friction and wear of different metallic materials, and to that end, several experiments have been carried out at both the microscale [5-12] and nanoscale [13-16]. 
At the microscale, the subsurface microstructure is affected by structural modifications due to the large plastic strain gradients generated during sliding of the surfaces in contact. These instabilities can lead to folding or cracking at the subsurface. An increase in the coefficient of friction (COF) is usually observed due to increased roughness at a sliding surface that is more easily plowed. Furthermore, wear debris particles may develop, and mechanical mixing/ alloying between these particles and the sliding surface can create a nanostructured tribomaterial that lowers the COF. At higher sliding cycles the COF may increase [17] due to delamination of this tribomaterial.

The adsorption of molecules under ambient conditions can lead to film formation at the surface and mechanical mixing with the near surface volume. The most frequently encountered state here is the formation of oxide films that are usually between 1 and $10 \mathrm{~nm}$ thick [18]. In such cases, the sliding behavior is controlled by the structure of these oxide films. If the oxide film is penetrated or removed during sliding, then the COF transitions rapidly to a value that is determined by the interaction of the base materials [19]. However, if the oxide layer is not broken, the oxide accommodates the shear, and determines the friction force. In the presence of an oxide or another reaction-formed film at the interface, recorded COF values in air are often much lower than in vacuum. The higher friction under vacuum is often attributed to strong adhesion between contacting clean metal surfaces. Growth of junctions can also take place, depending on the ductility of the asperity material [20].

In this article, we present a systematic experimental study of the frictional behavior of $\mathrm{Au}-\mathrm{Ni}$ multilayer samples, with different interlayer spacing, under a well-controlled $\mathrm{N}_{2}$ atmosphere, and present a comprehensive comparison with our previous UHV results [21]. Because Au and Ni are immiscible under certain conditions (e.g. conditions provided during deposition of the layers in this study), they were chosen to analyze the effect of microstructure on friction [21]. We clarify what influence of the initial microstructure of these $\mathrm{Au}-\mathrm{Ni}$ multilayer samples is observed in a dry $\mathrm{N}_{2}$ environment.

\section{Experimental Procedure}

\subsection{Preparation and Characterization of $\mathrm{Au}-\mathrm{Ni}$ Multilayers}

Ex situ cleaning of Si wafers (100) took place in two steps. A tenside surfactant was used as the pre-cleaner in an effort to achieve rough cleaning of the substrates, followed by an acetone solution in an ultrasonic bath for $2 \mathrm{~h}$ for the final stage. To clean and activate the substrate surface, plasma etching was applied inside a physical vapor deposition
(PVD) chamber (Leybold Z550) for $2 \mathrm{~min}$ at an atmosphere of $0.5 \mathrm{~Pa} \mathrm{Ar}$ in $6 \mathrm{~N}$ and a power of $500 \mathrm{~W}$. Subsequently, the growth of $\mathrm{Ni}$ and $\mathrm{Au}$ layers with well-defined microstructures on Si substrates took place via magnetron sputtering at $0.4 \mathrm{~Pa} \mathrm{Ar}$ in $6 \mathrm{~N}$ purity atmosphere with $75 \mathrm{~mm}$ diameter elemental targets. The individual layer thicknesses were $10 \mathrm{~nm}, 20 \mathrm{~nm}, 50 \mathrm{~nm}$, or $100 \mathrm{~nm}$, and the number of layers was changed from 100 to 10 to fix the total layer thickness at $1 \mu \mathrm{m}$. In order to prevent possible oxidation, in all cases the topmost layer was $\mathrm{Au}$ followed by $\mathrm{Ni}$.

For the characterization of the friction-induced microstructure, multilayer samples were milled via focused ion beam (FIB) (FEI Helios Nanolab 650, now ThermoFisher, operated at $30 \mathrm{kV}$ ) following the procedure for in-situ lift out technique reported in [22]. The cross sections were prepared either parallel (longitudinal plane) or perpendicular (transverse plane) to the sliding direction. Figure 1 provides a survey of the cross-sectional view of the as-grown $\mathrm{Au}-\mathrm{Ni}$ multilayer samples using high annular angle dark field (HAADF) mode thorough the scanning transmission electron microscope (STEM) detector. The waviness seen between the $\mathrm{Au}$ and Ni layers is due to residual strains, possibly induced by the lattice mismatch $(\sim 15 \%)$ between these metals, as well as orientation dependent growth rates. To analyze the worn microstructures and investigate their subsurface chemistry (S)TEM (FEI Titan ChemiSTEM, operated at $200 \mathrm{kV}$ ) imaging, operated in both the bright field (BF) and the HAADF mode, in combination with the energy dispersive X-ray spectroscopy (EDXS) analyses were performed on the multilayer samples. TEM and high resolution (HR) TEM (FEI Tecnai F30, operated at $300 \mathrm{kV}$ ) were also used.

In order to identify the crystallographic features of the multilayer samples, X-ray diffraction (XRD) analysis was performed. The measurements were carried out using $\mathrm{CuK} \alpha_{1 / 2}$ radiation in Bragg-Brentano geometry at a Seifert PAD II diffractometer equipped with a Meteor 1D detector. The presence of $\mathrm{Au}$ (111) crystallographic planes and possible Ni (111) planes, which have similar diffraction angle with the (200) order of Au, was confirmed.

A commercial AFM (Veeco Dimension V, now Bruker) was used in contact mode to analyze the roughness of the uppermost layers of $\mathrm{Au}-\mathrm{Ni}$ multilayer samples to study the effects of layer thickness on surface roughness. Si cantilevers (Budget Sensors uncoated Tap300 series with a radius of curvature $<10 \mathrm{~nm}$, a resonant frequency of $300 \mathrm{kHz}$ and a spring constant of $40 \mathrm{~N} / \mathrm{m}$ ) were used. It was observed that the roughness increases only slightly with layer thickness.

A Hysitron TI 950 Triboindenter (Bruker) nanoindenter was used to determine the hardness of the as-grown $\mathrm{Au}-\mathrm{Ni}$ multilayer samples through indentation load-displacement curves. A Berkovich-type diamond triangular pyramidal indenter was used. It was observed that an increase in the 
Fig. 1 HAADF STEM crosssectional views of the as-grown $\mathrm{Au}-\mathrm{Ni}$ multilayers for interlayer spacings of $10 \mathrm{~nm}(\mathbf{a}), 20 \mathrm{~nm}$ (b), $50 \mathrm{~nm}(\mathbf{c})$ and $100 \mathrm{~nm}(\mathbf{d})$, respectively (a)

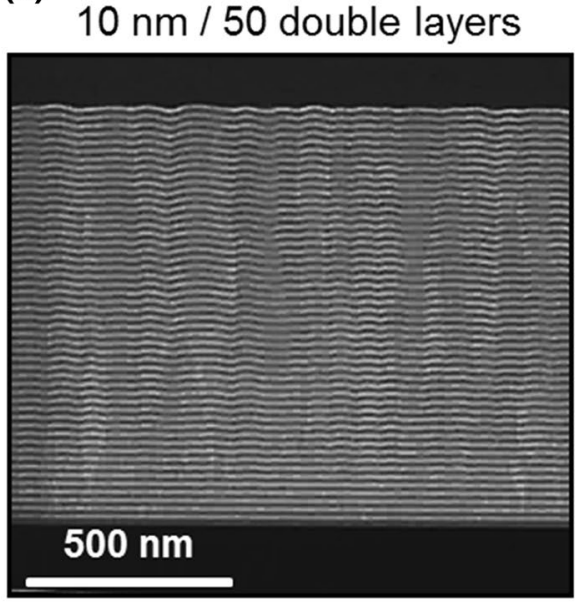

(c)

$50 \mathrm{~nm} / 10$ double layers

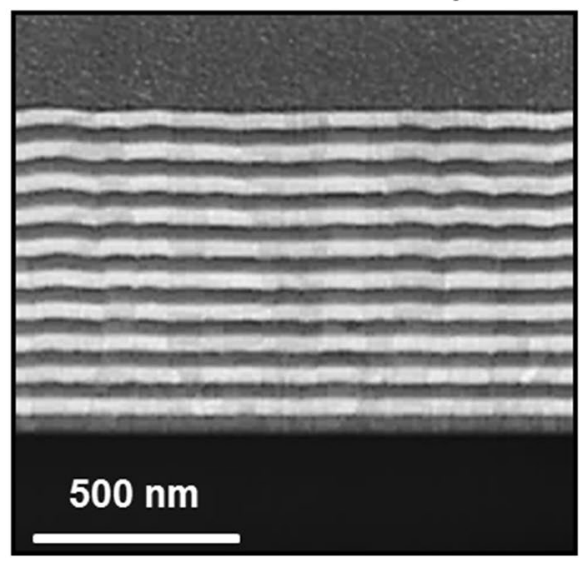

(b)

$20 \mathrm{~nm} / 25$ double layers

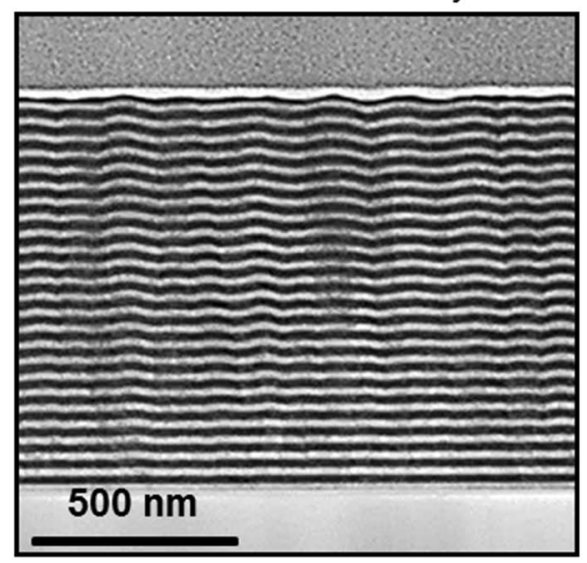

(d)

$100 \mathrm{~nm} / 5$ double layers

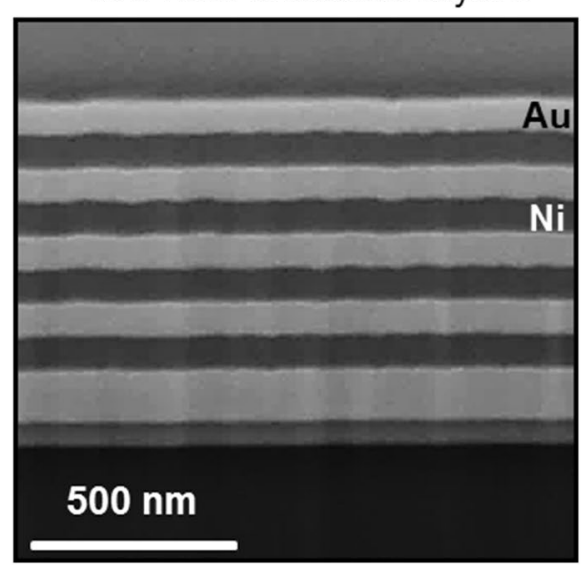

layer thickness from 10 to $100 \mathrm{~nm}$ leads to decrease in hardness of the multilayers by $58.3 \% \pm 7 \%$ at an $8 \mathrm{mN}$ indentation load.

\subsection{Microtribological Experiments}

A microtribometer in a polymer glove box, purged with dry $\mathrm{N}_{2}$ to $<10 \mathrm{ppm} \mathrm{O}_{2}$ and $<40 \mathrm{ppm}_{2} \mathrm{O}$, was used for friction experiments at ambient temperature. The relative humidity varied in the range of 10-20\% and the temperature was $20 \pm 1{ }^{\circ} \mathrm{C}$ during testing. A $1 \mathrm{mN}$ normal load was applied on an inert ruby sphere $(3.2 \mathrm{~mm}$ in diameter) and slid against a flat silicon wafer coated with $\mathrm{Au}-\mathrm{Ni}$ multilayers at $33 \mu \mathrm{m} / \mathrm{s}$ for 100 reciprocating cycles, using a stroke length of $1 \mathrm{~mm}$. The tribometer consists of a twoaxis double-leaf spring cantilever where friction and normal force are determined using capacitance probes that measure displacement of the calibrated cantilever (further details are found in [23]).

\section{Results}

\subsection{Frictional Behavior}

Figure 2 a shows the friction coefficient as a function of cycle number. For all experiments, the friction coefficient drops after the first few cycles, and for some multilayer samples the COF decreases gradually (e.g., $10 \mathrm{~nm}$ layer spacing), while for others it decreases suddenly. The experiments on multilayer samples with 20 and $50 \mathrm{~nm}$ layer spacings still showed unstable behavior towards the end of the experiments, whereas for the other systems stable friction was observed within the last 20 cycles. As shown in Fig. 2b, c, the COF increases with increasing layer thickness at the last cycle (Fig. 2b) and when averaged over the last five cycles (Fig. 2c). In the remainder of the paper we will not discuss the friction during run-in of the films, and focus only the steady-state behavior. 
(a)

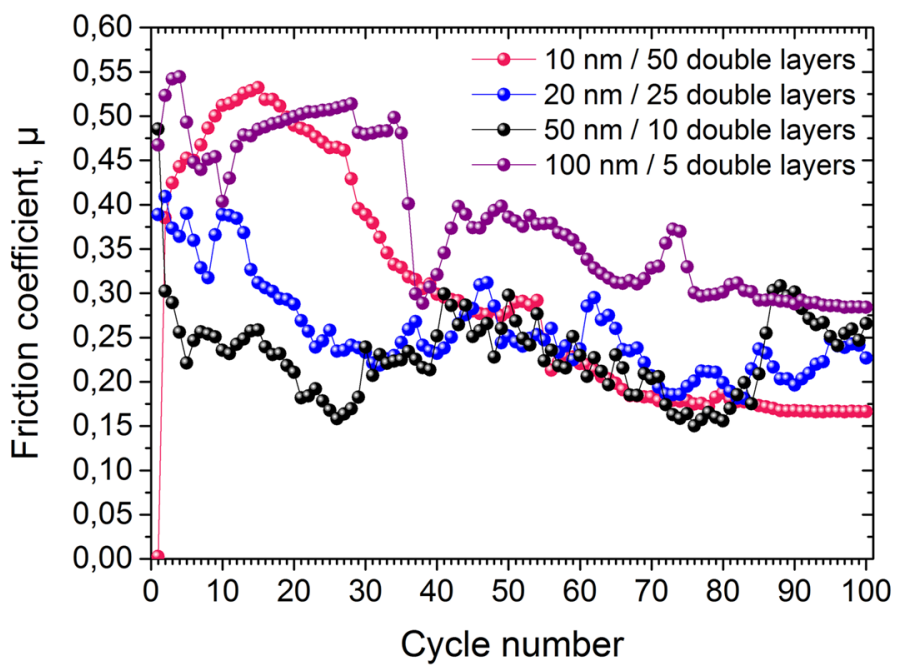

(b)

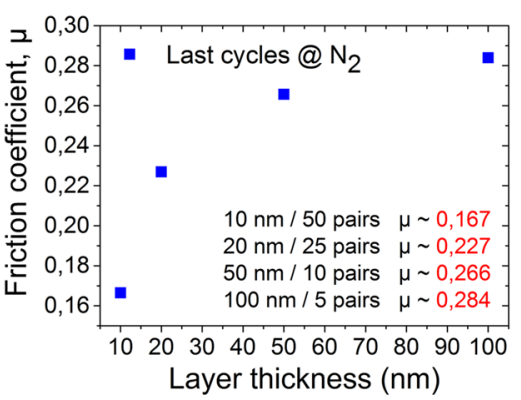

(c)

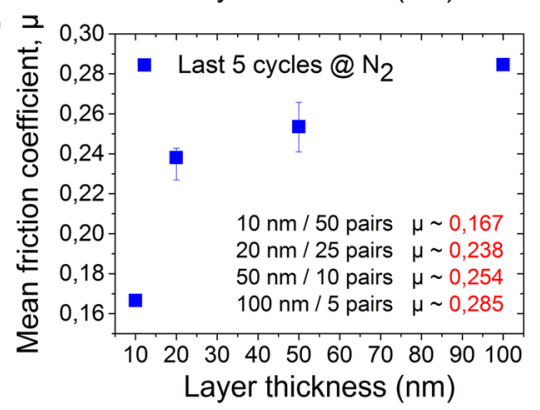

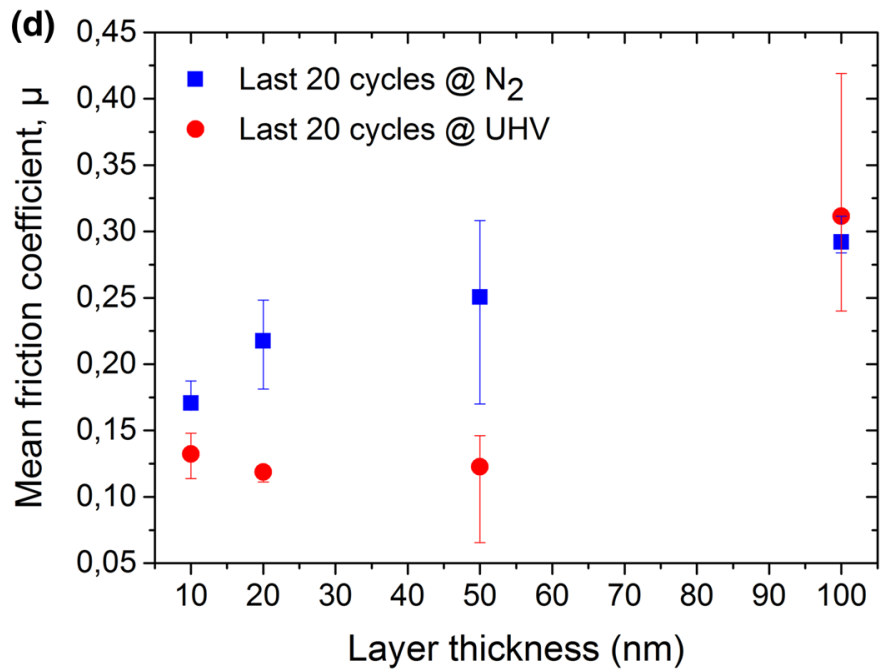

Fig. 2 Frictional behavior of Au-Ni multilayers. a Different frictional stability was found throughout sliding for 100 reciprocating cycles. For all tribological systems the friction coefficient drops after the first few cycles. The COF decreases gradually for the systems with 10 or $100 \mathrm{~nm}$ layer spacing while for others, the friction decreases suddenly. The 20 and $50 \mathrm{~nm}$ layer spacings still showed rather unstable friction behavior towards the end of the experiment, whereas for the other systems stable friction was observed within the last 20 cycles. A significant increase of the COF with increasing layer thickness is

\subsection{Microstructure Evolution of Worn Multilayers}

Figure $3 \mathrm{a}, \mathrm{b}$ presents the cross-sectional micrographs of the $10 \mathrm{~nm}$ sample after the friction experiment. In contrast to the previous experiments in UHV, we did not observe any kind of intermixing between $\mathrm{Au}$ and Ni layers, as shown in the EDXS maps in Fig. 3c, d. Only the first Au layer was affected, hereafter referred to as the tribolayer (i.e., the clear in the last cycle (b) and averaged over the last five cycles (c). Error bars in $\mathbf{c}$ were determined by the fluctuations in friction behavior during sliding as shown in a. d Comparison of the COF values between UHV conditions and $\mathrm{N}_{2}$ atmosphere averaged over the last 20 sliding cycles. The COF values for the $\mathrm{N}_{2}$ atmosphere were larger than that observed under UHV conditions, except the $100 \mathrm{~nm}$ sample. Error bars in $\mathbf{d}$ were determined by the fluctuations in friction behavior during sliding as shown in a and in [21]

region affected by the tribological stress), having around $20 \mathrm{~nm}$ thickness separated from the remaining material. The corresponding EDXS maps revealed the existence of $\mathrm{Au}$ (Fig. 3c) and the absence of Ni (Fig. 3d) in the tribolayer.

The detailed structural analysis of the $20 \mathrm{~nm}$ sample is displayed in Fig. 4. While deformation was confined to the first $\mathrm{Au}$ layer, the following $\mathrm{Ni}$ layer remained undeformed (Fig. 4a, b). The affected Au layer grew in thickness from 
Fig. 3 Characterization of $\mathrm{Au}-$ Ni multilayers with $10 \mathrm{~nm}$ layer thickness after the friction test in $\mathrm{N}_{2}$ atmosphere. a HAADF STEM cross-section of the worn $10 \mathrm{~nm}$ multilayer sample. Detachment of the tribolayer was observed (red arrows). b HAADF STEM cross-section of the worn $10 \mathrm{~nm}$ multilayer sample. Corresponding EDXS map showing weight concentration of $\mathbf{c} \mathrm{Au}$ and $\mathbf{d} \mathrm{Ni}$ in the tribomaterial. All cross-sections were prepared parallel to the sliding direction (Color figure online)

Fig. 4 Characterization of AuNi multilayers with $20 \mathrm{~nm}$ layer thickness after the friction test in $\mathrm{N}_{2}$ atmosphere. a HAADF STEM cross-section of the worn $20 \mathrm{~nm}$ multilayer sample. b HAADF STEM cross-section of the worn $20 \mathrm{~nm}$ multilayer sample. Corresponding EDXS map showing weight concentration of $\mathbf{c} \mathrm{Au}$ and $\mathbf{d} \mathrm{Ni}$ in the tribomaterial. All cross-sections were prepared parallel to the sliding direction
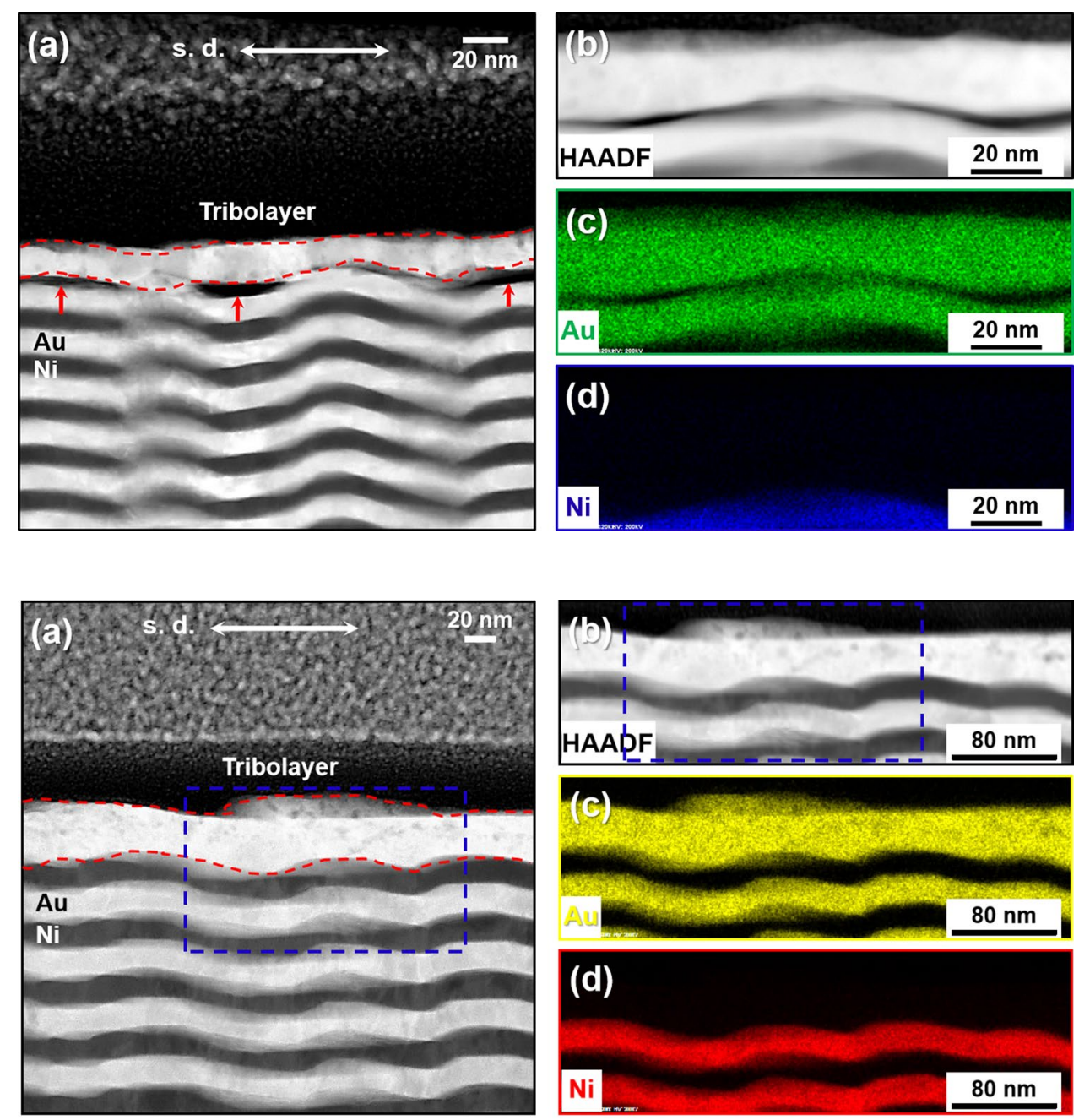

$20 \mathrm{~nm}$ to $40-45 \mathrm{~nm}$ during shearing, as shown in Fig. 4a. The corresponding EDXS maps revealed the presence of $\mathrm{Au}$ (Fig. 4c) and absence of Ni (Fig. 4d) in the tribolayer, again demonstrating the lack of mixing between the multilayers.

For the $50 \mathrm{~nm}$ multilayer sample shown in Fig. 5, we observed that the counter body (ruby ball) penetrated the top Au layer and only the bottom portion of the Au remained adhered to the Ni layer below. The cross-sectional STEM image perpendicular to the sliding direction in Fig. 5a depicts the worn portion of the top Au layer with the formation of a void. The HR-TEM image in Fig. 5b also shows the deformation of the uppermost Au layer, where damaged regions are indicated by the yellow arrow.

Figure 6 depicts the worn microstructure of the $100 \mathrm{~nm}$ sample subsequent to the friction test under $\mathrm{N}_{2}$ atmosphere. Comparing to the results of the $50 \mathrm{~nm}$ sample, little impact of the tribological stress was observed except for a thinning of the topmost Au layer by 10-30\%, as seen in Fig. 6a. Only the first Au layer was plastically deformed while subsequent layers were unaffected. The TEM image in Fig. 6b clearly shows the shear-deformed grains within the tribolayer.

\section{Discussion}

\subsection{Frictional Behavior of Au-Ni Multilayers in Different Environments}

As explained in detail in previous work [21], under welldefined UHV conditions the individual layer thickness of the Au-Ni multilayer systems has a strong impact on the resulting friction force. Under UHV, the multilayer samples with the thickness of $10 \mathrm{~nm}, 20 \mathrm{~nm}$, and $50 \mathrm{~nm}$ showed a low COF, while the $100 \mathrm{~nm}$ sample resulted in much higher friction under the same sliding conditions. On the other hand, performing the tests in a different environment resulted in different microstructural evolution for each sample except for the $100 \mathrm{~nm}$ interlayer spacing. As a result, the friction was different for all cases except for the latter one. Figure $2 \mathrm{~d}$ shows this difference between the multilayer samples sheared under different environmental conditions. Note that in Fig. 2a, the friction was highly variable as the number of sliding cycles changes 


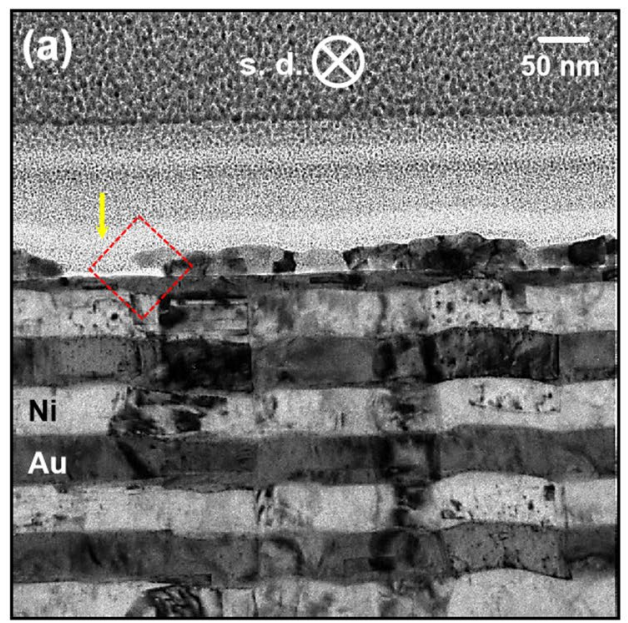

Fig. 5 Characterization of $\mathrm{Au}-\mathrm{Ni}$ multilayers with $50 \mathrm{~nm}$ layer thickness subsequent to the friction test in $\mathrm{N}_{2}$ atmosphere. a BF STEM cross-section of the worn $50 \mathrm{~nm}$ multilayer sample. b HR-TEM image, marked with the red dashed square in a, showing the damaged, crystalline tribolayer. Note that different appearances within the several zones in $\mathbf{b}$ caused by the mass-thickness contrast. Thicker

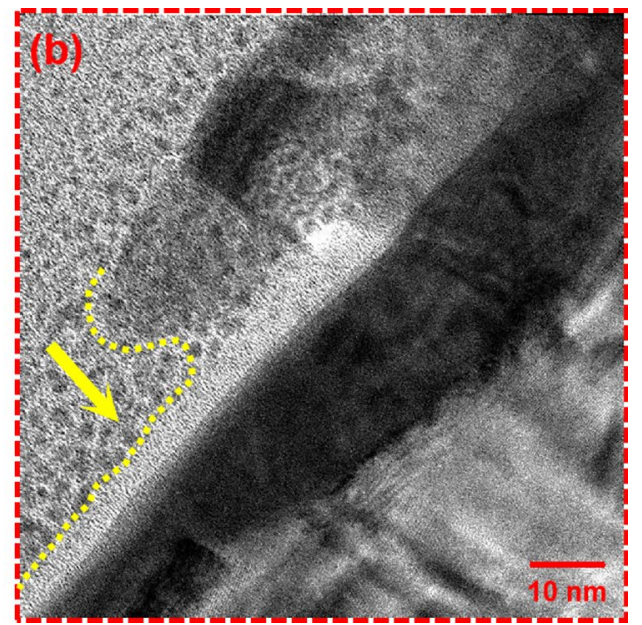

regions in the tribolayer (and the heavier $\mathrm{Au}$ ) in the sample appear dark while thinner regions in the tribolayer (and the lighter $\mathrm{Ni}$ ) in the sample appear with higher contrast. The top Au layer was completely missing in some regions with the formation of voids (yellow arrow in b). All cross-sections were prepared perpendicular to the sliding direction

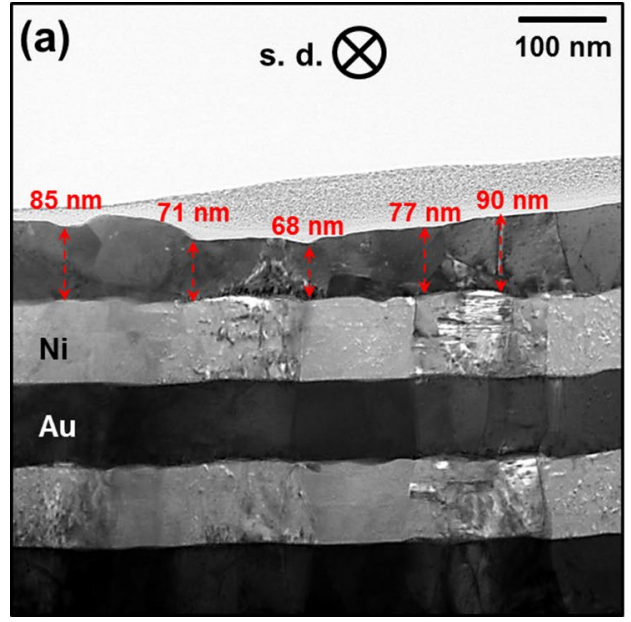

Fig. 6 Characterization of $\mathrm{Au}-\mathrm{Ni}$ multilayers with $100 \mathrm{~nm}$ layer thickness subsequent to the friction test in $\mathrm{N}_{2}$ atmosphere. a BF STEM cross-section of the worn $100 \mathrm{~nm}$ multilayer sample. Only the top Au layer was damaged. b TEM image showing the shear-induced microstructure in the tribolayer. The white arrows show the accumu-

in $\mathrm{N}_{2}$ atmosphere, although the COFs at the last cycles were more stable compared to the overall behavior. The final COF values obtained in $\mathrm{N}_{2}$ atmosphere were larger than those observed under UHV conditions in all cases except for the $100 \mathrm{~nm}$ sample. Interestingly, in $\mathrm{N}_{2}$, where mixing between the $\mathrm{Au}$ and $\mathrm{Ni}$ is suppressed, the $10 \mathrm{~nm}$, $20 \mathrm{~nm}$, and $50 \mathrm{~nm}$ samples show higher friction than in UHV. However there is little difference for the $100 \mathrm{~nm}$ sample, where the mixing is not present in either UHV or $\mathrm{N}_{2}$. Note that the lower friction forces for thinner interlayer

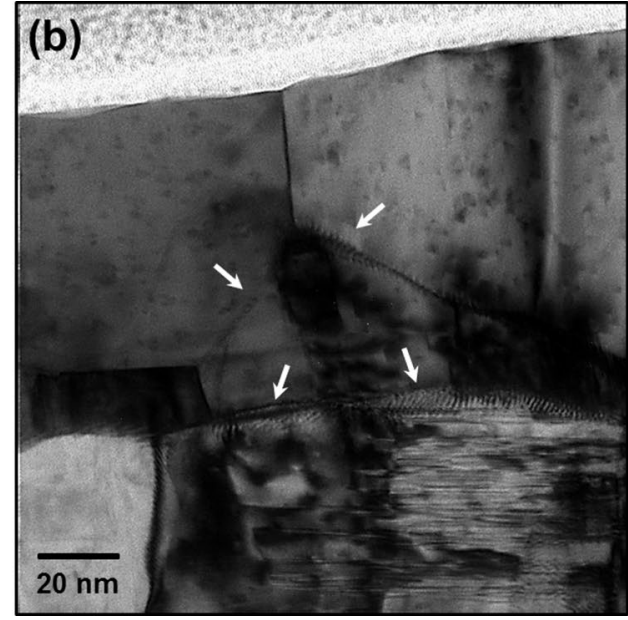

lation of dislocations at grain boundaries, supporting the conclusion that deformation mechanism is controlled by dislocation motion in this case. All cross-sections were prepared perpendicular to the sliding direction

spacings under UHV was attributed to the final microstructure resulting from the mechanical mixing of $\mathrm{Au}$ and $\mathrm{Ni}$ [21]. This mixing is likely linked to the dominant deformation mechanism [24, 25]. As we have already verified the ultrafine grain microstructure in the $10 \mathrm{~nm}$ sample via HRTEM [21], it is likely that grain sizes developed thorough the sliding experiments (due to mechanical mixing) under UHV must be smaller than those in $\mathrm{N}_{2}$ (except for the $100 \mathrm{~nm}$ sample), even though the latter experiments also led to changes in grain size; this is partially the cause of 
the fluctuations of the friction data. Because of the smaller overall grain size, lower friction was found under UHV conditions for thinner multilayer samples. Similarly, in $\mathrm{N}_{2}$, the lowest friction was observed in the $10 \mathrm{~nm}$ sample, and this thickness correlates with grains that are close to or smaller than the critical grain size [25].

\subsection{Microstructure Evolution of Au-Ni Multilayers in Different Environments}

When compared to the microstructural evolution observed under UHV [21], the experiments in nitrogen demonstrate the impact of environment on the resulting microstructure. No mechanical mixing of $\mathrm{Au}$ and $\mathrm{Ni}$ was observed for the multilayers slid in the nitrogen, in contrast with experiments in UHV. In nitrogen, only the uppermost Au layers were plastically deformed by plowing, and smearing of Au from other regions in the contact was seen for the samples with $10 \mathrm{~nm}$ and $20 \mathrm{~nm}$ layer thicknesses. As shown in Fig. 4a, for the $20 \mathrm{~nm}$ sample shearing has led to an increase in thickness by about a factor of two (thickness after sliding $40-45 \mathrm{~nm}$ ); this is most probably caused by plowing. A possible explanation for the thickening in this area of the contact can be the accumulation of the material plowed from other areas in contact. For the $10 \mathrm{~nm}$ sample, in addition to the thickening of the first Au layer, some parts of the tribolayer (around 15-20 nm) detached from the remainder, leaving a layer $<10 \mathrm{~nm}$ (Fig. 3a). This could be the result of higher localized stresses, as plastic deformation can induce the formation and nucleation of cracks beneath the contact, depending on the magnitude of the stress acting on the contacting surfaces [26]. Considering the observation of the $20 \mathrm{~nm}$ sample at the position where the FIB lamella was cut, it can be assumed that the detachment of the tribolayer is inhibited in thicker layers. We argue that the roughness of the ruby sphere could have led to different forces in different areas, and the position chosen to monitor the microstructural evolution is of significant importance. FIB cuts prepared parallel to the sliding direction for the $10 \mathrm{~nm}$ and $20 \mathrm{~nm}$ samples do not reveal the nature of the grooves on the wear track and thus allow us to only observe the plowing behavior throughout sliding. To study this, FIB cuts of the $50 \mathrm{~nm}$ and $100 \mathrm{~nm}$ samples were prepared perpendicular to the sliding direction, so that the grooves of the wear track can be observed. As seen in Fig. 5 for the $50 \mathrm{~nm}$ sample, the same amount of normal stress caused more damage in the top portion of the first Au layer, resulting in the formation of voids in the near-surface material. In contrast, the bottom portion was still adhered to the Ni underlayer. This groove (asperity) on the wear track is one of the more deeply plowed regions, and is likely responsible for local thickening due to the redistribution of the plowed material. Note that this effect is not seen in the other samples. Interestingly, there is overall less damage after sliding of the $100 \mathrm{~nm}$ sample due to the larger grain sizes in this system (Fig. 6). The amount of wear is estimated via the thinning of the multilayers.

Figure 7 compares wear tracks from the two different environments. Although similar structures were observed for both tracks, the environments resulted in quite different wear behavior. Much less wear was found for the multilayer samples sheared in $\mathrm{N}_{2}$ compared to that under UHV, leading to the different amount of deformation. Figure 7a, recorded via AFM, shows a plan view of the wear track for the $20 \mathrm{~nm}$ sample sheared under UHV. Lighter colors indicate higher topography whereas darker colors show deeper regions. The side view of the wear track shows that a depth of around $70-80 \mathrm{~nm}$ from the surface, in line with the previously discussed microstructural evolution, i.e., mechanical mixing of the $\mathrm{Au}$ and $\mathrm{Ni}$ [21]. In addition, a pile-up of material $100 \mathrm{~nm}$ thick is visible on the surface of the wear track. In contrast, in $\mathrm{N}_{2}$, there is less wear, as seen from the topographical image of the wear track in Fig. 7b. The side view of this track also reveals the lower wear, with a depth of only $20-25 \mathrm{~nm}$ (13 nm in some cases) from the surface, with several localized trenches. This analysis would also corroborate the microstructural evolution of the $20 \mathrm{~nm}$ sample sheared in $\mathrm{N}_{2}$, where no mixing of $\mathrm{Au}$ and $\mathrm{Ni}$ was observed (see the corresponding EDXS map). Correspondingly, less material pile-up $(\sim 30 \mathrm{~nm})$ was found on the surface of the wear track.

As stated above and in our previous publication [21], intermixing of $\mathrm{Au}$ and $\mathrm{Ni}$ layers has been observed in thinner multilayer samples in UHV, including the formation of a shear-induced AuNi alloy phase that does not exist in the binary phase diagram of the Au-Ni system [27]. Modifying the environment, however, led to different microstructural evolution, with no intermixing of $\mathrm{Au}$ and Ni layers. X-ray photoelectron spectroscopy (XPS) analysis shown in Fig. 8 reveals that carbon and oxygen are initially present on the topmost surface of the multilayer samples before the friction tests. Note that the multilayer samples were always cleaned via XPS/Ar ion sputtering prior to the friction tests under UHV conditions and the residual adsorbed gases (C and $\mathrm{O}_{2}$ peaks in the XPS spectrum) were removed. Since the current experiments were carried out under a $\mathrm{N}_{2}$ atmosphere, there are possible effects of the environment on the sliding contact region. For example, the adsorption of $\mathrm{N}_{2}$ [28] and $\mathrm{NO}_{2}$ [29] on Au surfaces has been observed, and the formation of $\mathrm{N}_{2} \mathrm{O}_{3}$ via the adsorption of $\mathrm{NO}_{2}$ has been seen on $\mathrm{Au}$ (111) [30]. Additionally, the presence of trace hydrocarbons has been shown to be more than sufficient to affect the friction of hard, smooth, and deformation resistant coatings [31]. Hence, the possibility of chemical interactions by hydrocarbons on the uppermost Au layers cannot be excluded in our experimental conditions. It might also be argued that a minute amount of water vapor in the $\mathrm{N}_{2}$ atmosphere $\left(<10 \mathrm{ppm} \mathrm{O}_{2}\right.$ and $<40 \mathrm{ppm}_{2} \mathrm{O}$ measured $)$ can 
(a)
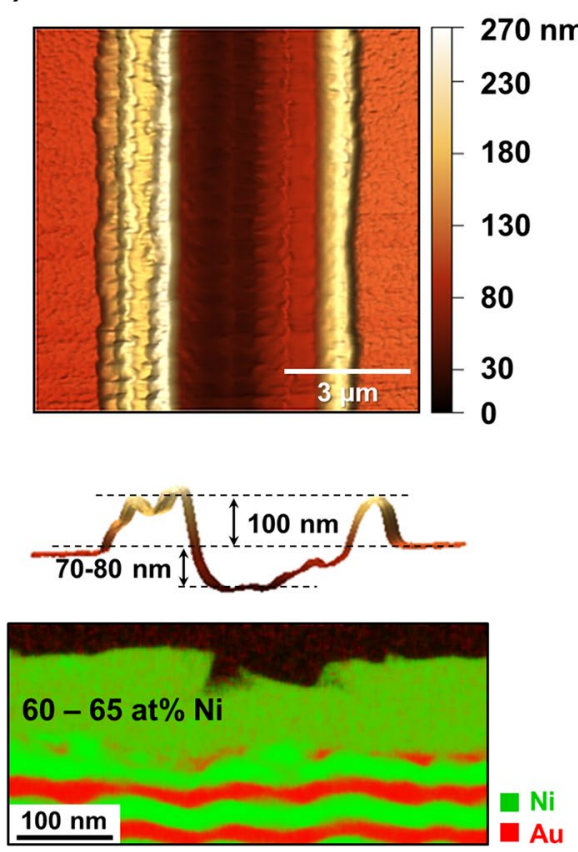

Fig. 7 AFM topography images of the wear tracks for the $20 \mathrm{~nm}$ sample after 100 reciprocating cycles of sliding under a UHV conditions and $\mathbf{b} \mathrm{N}_{2}$ atmosphere showing, from top to bottom, top view, side view of the height, and chemical analysis performed by EDXS. Plowing of the relatively soft multilayers with the hard ruby sphere leads to the creation of grooves in the wear tracks. The side view of the wear track in $\mathbf{a}$ is in agreement with the microstructure evolution

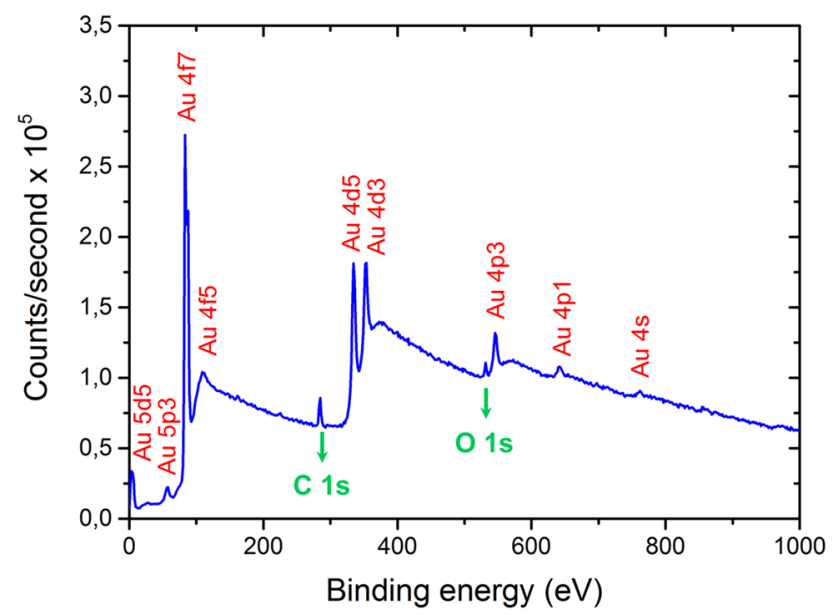

Fig. 8 XPS surface profiles of the Au-Ni multilayer sample. $\mathrm{C}$ and $\mathrm{O}_{2}$ peaks are present on the topmost surface before the friction test

affect the contact between the ruby sphere and the multilayer sample, if the adsorption of water on the initially clean surface of the sapphire [32] is taken into account. Considering this, the presence of water adlayers on the ruby surface could account for the lower wear of the multilayers by causing the (b)
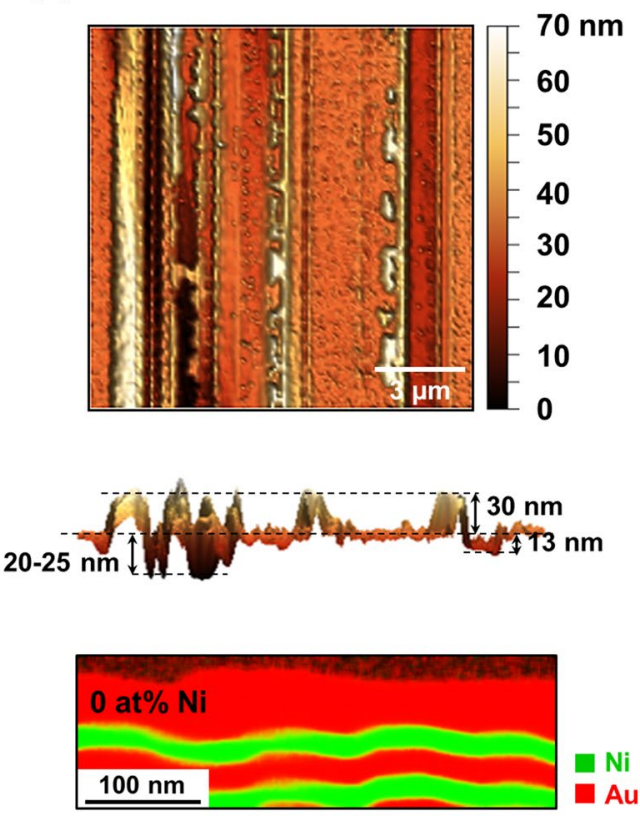

in UHV, where the layers of Au and Ni have mixed. Due to the direct contact between the ruby ball and the multilayer sample at the clean (uncontaminated) interface, the sphere has worn several $\mathrm{Au}$ and $\mathrm{Ni}$ layers resulting in mixing [21]. The side view of the track in $\mathbf{b}$ reveals the gentler wear on the sample surface in $\mathrm{N}_{2}$ environment. The direct contact at the interface is changed by adsorbates, so that only the topmost Au layer is influenced

shear to occur in the water layer on the ruby sphere. Due to the capillary effects of water, the contact area can increase at the interface, also leading to the observed higher friction in $\mathrm{N}_{2}$, compared to that in UHV.

In summary, these experiments suggest that adsorption of environmental species, even in a nominally clean $\mathrm{N}_{2}$ atmosphere; can increase the shear strength (i.e., from capillary forces, in the case of water) between the ruby ball and the multilayer sample. Due to the obvious impact of adsorbates on the apparent shear stresses, the effect of grain size on the friction in the thinner multilayer samples was smaller in dry $\mathrm{N}_{2}$ than in UHV, even though grain size changed in both conditions. On the other hand, contaminant-free UHV conditions enabled a stronger effect of the grain size on the friction, particularly in thinner multilayer samples, through the formation of a shear-induced AuNi alloy.

\section{Conclusion}

In this article, friction experiments performed on Au-Ni multilayer samples under dry, ultra-high purity $\mathrm{N}_{2}$ are reported, and are compared to previous results obtained under UHV [21]. The differences in environment impacted 
friction by increasing the $\mathrm{COF}$ in $\mathrm{N}_{2}$, likely due to the absence of grain refinement by mechanical alloying. The COFs of each multilayer system in $\mathrm{N}_{2}$ were larger than under $\mathrm{UHV}$, except for the $100 \mathrm{~nm}$ samples. Much lower wear was found for the multilayers sheared in $\mathrm{N}_{2}$, resulting in different amounts of deformation. No mixing was observed between the $\mathrm{Au}$ and Ni layers for thinner multilayer samples under $\mathrm{N}_{2}$, in contrast with UHV. Despite the environment being nominally inert, the role of trace hydrocarbons can have a remarkable impact on friction behavior when the rubbing surfaces are wear resistant and smooth [31]. While we found deformation of the uppermost Au layers from plowing of material throughout sliding, material transfer from other areas in the contact was also occasionally observed, leading to thickening of the tribolayer. The sublayers appeared unaffected for all samples. For the $10 \mathrm{~nm}$ sample only, detachment of the tribolayer was found.

Acknowledgements Open Access funding provided by Projekt DEAL. The authors gratefully acknowledge support from the Deutsche Forschungsgemeinschaft through the Heisenberg Programme (DI 1494/4-1 and DI 1494/5-1). Harald Leiste, Michael Stüber, and Sven Ulrich are gratefully acknowledged for their contribution to the growth of $\mathrm{Au}-\mathrm{Ni}$ multilayer samples and XRD characterization. The authors also thank Dominic Linsler and Eberhard Nold for the nanoindentation measurements and XPS analysis. This work was accomplished as part of the Research Travel Grant provided by the Karlsruhe House of Young Scientists (KHYS) of KIT. The authors also acknowledge the Sandia National Laboratories Laboratory Directed Research and Development (LDRD) program for funding this work. This work was performed, in part, at the Center for Integrated Nanotechnologies, an Office of Science User Facility operated for the U.S. Department of Energy (DOE) Office of Science. Sandia National Laboratories is a multi-mission laboratory managed and operated by National Technology and Engineering Solutions of Sandia, LLC., a wholly owned subsidiary of Honeywell International, Inc., for the U.S. Department of Energy's National Nuclear Security Administration under contract DE-NA-0003525. The views expressed in the article do not necessarily represent the views of the U.S. DOE or the United States Government.

Open Access This article is licensed under a Creative Commons Attribution 4.0 International License, which permits use, sharing, adaptation, distribution and reproduction in any medium or format, as long as you give appropriate credit to the original author(s) and the source, provide a link to the Creative Commons licence, and indicate if changes were made. The images or other third party material in this article are included in the article's Creative Commons licence, unless indicated otherwise in a credit line to the material. If material is not included in the article's Creative Commons licence and your intended use is not permitted by statutory regulation or exceeds the permitted use, you will need to obtain permission directly from the copyright holder. To view a copy of this licence, visit http://creativecommons.org/licenses/by/4.0/.

\section{References}

1. Roberts, E.W.: Space tribology: its role in spacecraft mechanisms. J. Phys. D 45, 503001 (2012)
2. Gola, A.: Deformation of metallic multilayers: an atomistic study of the relationship between structure and deformation mechanisms. Karlsruhe (2019)

3. Godet, M.: The third body approach: a mechanical view of wear. Wear 100, 437-452 (1984)

4. Bowden, F.P., Tabor, D.: Mechanism of metallic friction. Nature 150, 197-199 (1942)

5. Lancaster, J.K.: A review of the influence of environmental humidity and water on friction, lubrication and wear. Tribol. Int. 23(6), 371-389 (1990)

6. Grillo, S.E., Field, J.E.: The friction of CVD diamond at high Hertzian stresses: the effect of load, environment and sliding velocity. J. Phys. D 33, 595-602 (2000)

7. Kim, H.I., Lince, J.R., Eryilmaz, O.L., Erdemir, A.: Environmental effects on the friction of hydrogenated DLC films. Tribol. Lett. 21(1), 51-56 (2006)

8. Li, H., Xu, T., Wang, C., Chen, J., Zhou, H., Liu, H.: Tribochemical effects on the friction and wear behaviors of a-C: $\mathrm{H}$ and a-C films in different environment. Tribol. Int. 40(1), 132-138 (2007)

9. Dudder, G.J., Zhao, X., Krick, B., Sawyer, W.G., Perry, S.S.: Environmental effects on the tribology and microstructure of $\mathrm{MoS}_{2}-$ $\mathrm{Sb}_{2} \mathrm{O}_{3}-\mathrm{C}$ films. Tribol. Lett. 42(2), 203-213 (2011)

10. Stoyanov, P., Stemmer, P., Järvi, T.T., Merz, R., et al.: Friction and wear mechanisms of tungsten-carbon systems: a comparison of dry and lubricated conditions. ACS Appl. Mater. Interfaces 5, 6123-6135 (2013)

11. Cui, L., Lu, Z., Wang, L.: Environmental effect on the loaddependent friction behavior of a diamond-like carbon film. Tribol Int. 82, 195-199 (2015)

12. Marchetto, D., Feser, T., Dienwiebel, M.: Microscale study of frictional properties of graphene in ultra high vacuum. Friction 3(2), 161-169 (2015)

13. Stempflé, P., Stebut, J.: Nano-mechanical behaviour of the 3rd body generated in dry friction-feedback effect of the 3rd body and influence of the surrounding environment on the tribology of graphite. Wear 260(6), 601-614 (2006)

14. Mougin, K., Gnecco, E., Rao, A., Cuberes, M.T., Jayaraman, S., McFarland, E.W., Haidara, H., Meyer, E.: Manipulation of gold nanoparticles: influence of surface chemistry, temperature, and environment (vacuum versus ambient atmosphere). Langmuir 24(4), 1577-1581 (2008)

15. Greiner, C., Felts, J.R., Dai, Z., King, D.P., Carpick, R.W.: Controlling nanoscale friction through the competition between capillary adsorption and thermally activated sliding. ACS Nano 6(5), 4305-4313 (2012)

16. Egberts, P., Ye, Z., Liu, X.Z., Dong, Y., Martini, A., Carpick, R.W.: Environmental dependence of atomic-scale friction at graphite surface steps. Phys. Rev. B 88, 035409 (2013)

17. Chen, X., Han, Z., Li, X., Lu, K.: Lowering coefficient of friction in $\mathrm{Cu}$ alloys with stable gradient nanostructures. Sci. Adv. 2, 1601942 (2016)

18. Hutchings, I., Shipway, P.: Tribology: Friction and Wear of Engineering Materials. Elsevier, Cambridge (2017)

19. Buckley, D.H.: Surface Effects in Adhesion, Friction Wear and Lubrication. Tribology, vol. 5. Elsevier, Amsterdam (1981)

20. Tabor, D.: Junction growth in metallic friction: the role of combined stresses and surface contamination. Proc. R. Soc. Lond. Ser. A 251, 378-393 (1959)

21. Cihan, E., Störmer, H., Leiste, H., Stüber, M., Dienwiebel, M.: Low friction of metallic multilayers by formation of a shearinduced alloy. Sci. Rep. 9(9480), 1-10 (2019)

22. Giannuzzi, L.A., Stevie, F.A.: A review of focused ion beam milling techniques for TEM specimen preparation. Micron 30(3), 197-204 (1999) 
23. Zeng, G., Tan, C.K., Tansu, N., Krick, B.A.: Ultralow wear of gallium nitride. Appl. Phys. Lett. 109(5), 1-6 (2016)

24. Yamakov, V., Wolf, D., Phillpot, S.R., Mukherjee, A.K., Gleiter, H.: Deformation-mechanism map for nanocrystalline metals by molecular-dynamics simulation. Nat. Mater. 3, 43-47 (2004)

25. Argibay, N., Chandross, M., Cheng, S., Michael, J.R.: Linking microstructural evolution and macro-scale friction behavior in metals. J. Mater. Sci. 52, 2780-2799 (2017)

26. Suh, N.P.: Update on the delamination theory of wear. In: Rigney, D.A. (ed.) Fundamentals of Friction and Wear of Materials, pp. 43-71. ASM, Pittsburgh (1981)

27. Raynor, G.V.: The alloying behaviour of gold. Gold Bull.: J. Gold Sci. Technol. Appl. 9(1), 12-19 (1976)

28. Krim, J., Dash, J.G., Suzanne, J.: Triple-point wetting of light molecular gases on Au (111) surfaces. Phys. Rev. Lett. 52, 640643 (1984)

29. Wickham, D.T., Banse, B.A., Koel, B.E.: Adsorption of nitrogen dioxide on polycrystalline gold. Catal. Lett. 6, 163-172 (1990)
30. Bartram, M.E., Koel, B.E.: The molecular adsorption of $\mathrm{NO}_{2}$ and the formation of $\mathrm{N}_{2} \mathrm{O}_{3}$ on $\mathrm{Au}$ (111). Surf. Sci. 213, 137-156 (1989)

31. Argibay, N., Babuska, T.F., Curry, J.F., Dugger, M.T., Lu, P., Adams, D.P., et al.: In-situ tribochemical formation of self-lubricating diamond-like carbon films. Carbon 138, 61-68 (2018)

32. Schildbach, M.A., Hamza, A.V.: Clean and water-covered sapphire (1102) surfaces: structure and laser-induced desorption. Surf. Sci. 282, 306-322 (1993)

Publisher's Note Springer Nature remains neutral with regard to jurisdictional claims in published maps and institutional affiliations. 